\title{
Türk ve Mülteci Gebelerde HBsAg, Anti-HBs, Anti-HCV ve Anti-HIV Seropozitifliklerinin Karşılaştırılması
}

\author{
Sibel MUTLU [i] ${ }^{1}$, Şerife YILMAZ [i] ${ }^{2}$
}

\section{ÖZ}

Amaç: Bu çalışmada amacımız bölgemizdeki gebelerde HBsAg, anti-HBs, anti-HCV ve anti-HIV seropozitifliğini belirlemek ve mülteci gebeler ile Türk gebelerin sonuçlarını karşılaştırmaktır.

Gereç ve Yöntemler: Çalışmamızda 2017-2019 tarihleri arasında Karabük Üniversitesi Eğitim Araştırma Hastanesi'ne başvuran Türk ve mülteci gebelerin HBsAg, anti-HBs, anti-HCV ve anti-HIV sonuçları retrospektif olarak irdelenmiş ve iki grup arasında karşılaşıtırma yapılmıştır.

Bulgular: Çalışmamıza 3382 gebe dahil edilmiş olup $3152(\% 93,2)$ si Türk, $230(\% 6,8)$ u mülteci gebelerden oluşmaktadır. Tüm gebelerde HBsAg, anti-HBs, anti-HCV ve anti-HIV seropozitifliği sırasıyla $\% 0,68 ; \% 37,2 ; \% 0,08$ ve $\% 0$ dır. Türk gebeler ile mülteci gebeler arasında anti-HBs seropozitiflik oranı sırasıyla $\% 38,4$ ve $\% 22,2$ olup aradaki fark anlamlı bulunmuştur $(\mathrm{p}<0,001)$. Türk gebelerde 20 yaş ve altı ve 21-30 yaş arası gebelerde anti-HBs seropozitifliği sırasıyla \%44,4 ve \%61,2 iken, 31-40 yaş arası ve 40 yaş üstü gebelerde sırasıyla $\% 14,4$ ve $\% 19,4$ dür. Yaş grupları arasındaki bu farklılık istatistiksel olarak anlamlı bulunmuştur $(\mathrm{p}<0,001)$.

Sonuç: Türk gebe kadınlarda anti-HBs seropozitifliği mülteci gebelere göre anlamlı düzeyde yüksek oranda bulunmuştur. Bu nedenle özellikle mülteci gebeler için Hepatit B aşılama programları düzenli olarak takip edilmeli ve rutin tarama yapılmalıdır. Çalışmamızda düşük oranda anti-HCV pozitifliği saptanmış ve anti-HIV seropozitifliğine rastlanmamıştır. Ancak yine de bu enfeksiyonlar ülkemizde görülmeye devam ettiğinden ve önlem alındığında anneden bebeğe geçişin azalması sağlanacağından anti-HCV ve anti-HIV taramasına devam edilmelidir.

Anahtar Kelimeler: Gebelik; hepatit B; hepatit C; HIV.

\section{Comparison of HBsAg, Anti-HBs, Anti-HCV and Anti-HIV Seropositivity of Turkish and Refugee Pregnant Women}

\begin{abstract}
Aim: Our aim is to investigate the seropositivity of HBsAg, anti-HBs, anti-HCV and anti-HIV in pregnant women and compare the seropositivity of these parameters of refugee and Turkish pregnant women in our region.

Material and Methods: In our study, HBsAg, anti-HBs, anti-HCV and anti-HIV results of Turkish and refugee pregnant women who presented at Karabuk University Training and Research Hospital between 2017-2019 were analyzed and compared retrospectively.

Results: The 3382 pregnant women were comprised of 3152 (93.2\%) Turkish and 230 (6.8\%) refugee pregnant women. In all pregnant women, the rates of HBsAg, anti-HBs, anti-HCV and anti-HIV seropositivity were $0.68 \%, 37.2 \%$, $0.08 \%$ and $0 \%$, respectively. The rates of anti-HBs seropositivity between Turkish and refugee pregnant women were $38.4 \%$ and $22.2 \%$, respectively, and the difference was significant $(\mathrm{p}<0.001)$. While anti-HBs seropositivity was found as $44.4 \%$ and $61.2 \%$ in the age groups $\leq 20$ years and $21-30$ years respectively, it is $14.4 \%$ and $19.4 \%$ in the age groups $31-40$ years and over 40 years respectively. This difference between age groups was statistically significant $(\mathrm{p}<0.001)$.

Conclusion: Seropositivity of anti-HBs was significantly higher in Turkish pregnant women than refugee pregnant women. Therefore especially for refugee pregnant women, hepatitis B vaccination programs should be followed up regularly and routine screening should be organized. In our study, a low rate of anti-HCV seropositivity was detected
\end{abstract}

1 Karabük Üniversitesi Tıp Fakültesi Jinekoloji ve Obstetrik Anabilim Dalı, Karabük, Türkiye

2 Karabük Eğitim ve Araştırma Hastanesi Mikrobiyoloji Laboratuvarı, Karabük, Türkiye

Sorumlu Yazar / Corresponding Author: Sibel MUTLU, e-mail: drsibelmutlu@yahoo.com.tr Geliş Tarihi / Received: 20.04.2020, Kabul Tarihi / Accepted: 14.12.2020 
and anti-HIV seropositivity was not detected. However, anti-HCV and anti-HIV screening should be continued since these infections occur in our country and transmission from mother to infant will be reduced when protective measures are taken.

Keywords: Pregnancy; hepatitis B; hepatitis C; HIV.

\section{GIRIS}

Gebelik döneminde ortaya çıkan viral enfeksiyonlar plasentayı aşarak fetüse bulaşabilmekte ve fetal mortalite ve morbiditeyi arttırabilmektedir (1). Hepatit B virüsü (HBV) bulaşının da en önemli nedenlerinden biri anneden bebeğe geçiş olup ülkemizde de bu yolla geçişin yaygın olduğu bilinmektedir (2). Perinatal yolla enfekte olan bebeklerde HBV \% 90 lara varan oranlarda kronikleşebilmektedir (3). Hastalık Önleme ve Kontrol Merkezi (CDC) ve Dünya Sağlık Örgütü tarafindan 1984 yılından beri tüm gebelerin Hepatit B yüzey antijen (HBsAg) yönünden taranması ve annenin hepatit B taşıyıcısı olması halinde aşı ve hepatit B immune globulinin (HBIG) birlikte uygulanması gerektiği bildirilmektedir $(4,5)$.

Hepatit $\mathrm{C}$ virüsü (HCV) ise dünya genelinde gebelerin \%8 ini etkilemektedir ve HCV ile enfekte annelerden doğan bebeklerde perinatal bulaş oranı \%2,7-8,4 arasındadır. Gebelerde HCV enfeksiyonu varlığ infantlarda gebelik yaşına göre küçük bebek, düşük doğum ağırlığı ve yenidoğan yoğun bakım ünitesine yatış gibi olumsuz sonuçlara neden olabilmektedir (6-8).

İnsan Bağışıklık Yetmezlik Virüsü (HIV) ile enfekte gebe popülasyonu da günümüzde giderek artmaktadır. Bu nedenle CDC gebelerde HIV enfeksiyonu taraması yapılmasını önermektedir. HIV pozitif gebelerin tespit edilmesi ve perinatal geçişin azaltılması için uygun antiretroviral tedavi olanaklarının sağlanması ve gerekli önlemlerin alınması oldukça önemlidir $(9,10)$.

Ülkemizde HBV, HCV ve HIV seropozitifliği bölgeler arası değişiklik göstermektedir (11). İlimiz hastanesi Batı Karadeniz Bölgesinin üçüncü basamak sağlık merkezlerinden biri olup çevre illerden de birçok hasta başvurmaktadır. Ayrıca ilimize başka ülkelerden göç eden on bine yakın mülteci bulunmaktadır.

$\mathrm{Bu}$ çalışmada amacımız bölgemizdeki gebelerde HBsAg, anti-HBs, anti-HCV ve anti-HIV seropozitifliğini belirlemek ve mülteci gebeler ile Türk gebelerin sonuçlarını karşılaştırmaktır.

\section{GEREÇ VE YÖNTEMLER}

Çalışmamız retrospektif olup bu çalışmaya 2017-2019 tarihleri arasında Karabük Üniversitesi Eğitim Araştırma Hastanesi'ne başvuran tüm Türk ve mülteci gebelerin HBsAg, anti-HBs, anti-HCV ve anti-HIV sonuçları dahil edildi. Tekrarlayan sonuçlar çalışma dişı bırakıldı. Çalışmamız için test sonuçları Mikrobiyoloji laboratuvar bilgi sisteminden elde edildi. Gebeler 20 yaş ve alt1, 21$30,31-40$ ve 40 yaş üstü olmak üzere toplam dört gruba ayrild1.

Mikrobiyoloji laboratuvarına gönderilen serum örneklerinde HBsAg, anti-HBs, anti-HCVve anti-HIV testleri ARCHITECT i2000 SR (Abbott Diagnostics, USA) cihazında kemiluminesans yöntemle çalışıldı. Çalışmamızın etik kurul izini; Karabük Üniversitesi girişimsel olmayan klinik araştırmalar etik kurulundan
29.05.2020 tarih ve 77192459-050.99-E.19542 sayılı kararı ile alınmıştır.

\section{İstatistiksel Analiz}

Çalışmada elde edilen verilerin istatistiksel analizi için SPSS 22.0 programı (SPSS Inc, Armonk, NY, ABD) kullanılmıştır. Tanımlayıcı istatistikler sayı (n) ve yüzde (\%) olarak ifade edilmiştir. Grup karşılaştırmaları için Pearson ki-kare testi ve Fisher exact testi kullanılmıştır. $\mathrm{P}<0,05$ değeri istatistiksel olarak anlamlı kabul edilmiştir.

\section{BULGULAR}

Çalışmamıza 2017-2019 yıllarında hastanemize başvuran 3382 gebe dahil edilmiş olup $3152(\% 93,2)$ si Türk, 230 $(\% 6,8)$ u mülteci gebelerden oluşmaktadır. Gebelerin yaş ortalaması $30,48 \pm 5,7$ dir. Türk gebelerin yaş ortalaması $26 \pm 1,41$; mülteci gebelerin yaş ortalaması $24 \pm 4,24$ her iki grup arasında fark yoktur $(\mathrm{p}=0,101)$. Tüm gebelerde HBsAg, anti-HBs, anti-HCV ve anti-HIV seropozitifliği sirasiyla $\% 0,68 ; \% 37,2 ; \% 0,08$ ve $\% 0$ dir. Türk ve mülteci gebelerin HBsAg, anti-HBs, anti-HCV ve antiHIV pozitiflik oranlarının karşılaştırılması Tablo 1 de gösterilmiştir. Türk gebeler ile mülteci gebeler arasında anti-HBs seropozitiflik oranı sirasıyla $\% 38,4$ ve $\% 22,2$ olup aradaki fark anlamlı bulunmuştur $(\mathrm{p}<0,001)$.

Tablo 1. Türk ve mülteci gebelerde HBsAg, anti-HBs, anti-HCV ve anti-HIV seropozitiflikleri

\begin{tabular}{|c|c|c|c|c|c|}
\hline & \multicolumn{2}{|c|}{$\begin{array}{c}\text { Türk gebe } \\
\text { (n=3152) }\end{array}$} & \multicolumn{2}{c|}{$\begin{array}{c}\text { Mülteci gebe } \\
\text { (n=230) }\end{array}$} & \multirow{2}{*}{ P değeri } \\
\cline { 2 - 5 } & $\mathbf{n}$ & $\mathbf{\%}$ & $\mathbf{n}$ & $\mathbf{\%}$ & \\
\hline $\begin{array}{c}\text { HBsAg } \\
(+)\end{array}$ & 21 & 0,66 & 2 & 0,87 & 0,235 \\
\hline $\begin{array}{c}\text { Anti-HBs } \\
(+)\end{array}$ & 1210 & 38,4 & 51 & 22,2 & $\mathbf{0 , 0 0 1}$ \\
\hline $\begin{array}{c}\text { Anti- } \\
\text { HCV (+) }\end{array}$ & 2 & 0,06 & 1 & 0,43 & 0,240 \\
\hline $\begin{array}{c}\text { Anti-HIV } \\
(+)\end{array}$ & - & - & - & - & \\
\hline
\end{tabular}

Hepatit B Yüzey Antikoru, Anti-HIV: Human Immunodeficiency Virus Yüzey Antikoru $\mathrm{P}<0,05$ değeri istatistiksel olarak anlamlı kabul edilmiştir.

Yaş gruplarına göre Türk ve mülteci gebelerde HBsAg ve anti-HBs seropozitiflikleri Tablo 2 de belirtilmiştir. Türk gebelerde yaş grupları arasındaki anti-HBs seropozitiflikleri arasındaki fark anlamlı bulunmuştur $(\mathrm{p}<0,001)$.

\section{TARTISMA VE SONUÇ}

Dünya Sağlık Örgütü'nün son verilerine göre 240 milyona yakın insan kronik hepatit B enfeksiyonu geçirmekte ve her yıl yaklaşık 600,000 kişi yaşamını yitirmektedir. $\mathrm{Bu}$ kişilerin \%21'inin perinatal dönemde, \%48'inin ise beş yaş altı dönemde enfekte olduğu bilinmektedir. Ülkemiz hepatit B sıklığı açısından orta endemik bölgeler içinde sayılmaktadır. Türkiye'de gebelerde yapılan çalışmalara baktığımızda HBsAg seropozitifliğini Madendağ ve ark. (12)

\%2,11; Aynığlu ve ark. (13) \%4; İnci ve ark. (14) \% 1,4 oranında bulmuşlardır. Yakın zamanlı bir çalışmada ise 
Suriyeli gebelerle Türk gebeler arasında HBsAg seropozitifliği karşılaştırılmış ve Türk gebelerde \% 1,8; mülteci gebelerde $\% 1,1$ oranında pozitiflik bulunmuştur (1). Çalışmamızda tüm gebelerde HBsAg seropozitifliği \%0,68 olup Türk ve mülteci gebelerde bu oran birbirine yakındır. Türkiye verilerine göre bu oranın daha düşük olması bölgesel farklılıklarla ilişkilendirilebilir.

Tablo 2. Yaş gruplarına göre Türk ve mülteci gebelerde HBsAg ve anti-HBs seropozitiflikleri

\begin{tabular}{|c|c|c|c|c|}
\hline & $\begin{array}{c}\text { Yaş } \\
\text { grupları }\end{array}$ & $\begin{array}{c}\begin{array}{c}\text { HBsAg } \\
\text { pozitif }\end{array} \\
\text { n (\%) }\end{array}$ & $\begin{array}{c}\text { Anti-HBs } \\
\text { pozitif } \\
\text { n (\%) }\end{array}$ & Toplam \\
\hline \multirow{4}{*}{ مُ } & $\leq 20$ & $1(1,8)$ & $24(44,4)$ & 54 \\
\hline & $21-30$ & $13(0,8)$ & $956(61,2)$ & 1560 \\
\hline & $31-40$ & $6(0,4)$ & $201(14,4)$ & 1389 \\
\hline & $>40$ & $1(0,6)$ & $29(19,4)$ & 149 \\
\hline \multirow{4}{*}{ 氖苞 } & $\leq 20$ & - & $4(18,2)$ & 22 \\
\hline & $21-30$ & $2(1)$ & $36(23,2)$ & 155 \\
\hline & $31-40$ & - & $10(20,4)$ & 49 \\
\hline & $>40$ & - & $1(25)$ & 4 \\
\hline
\end{tabular}

Aşılama HBV'ye karşı en etkili korunma yöntemidir. Ülkemizde aşı kapsayıcılığı son yıllarda giderek artmış ve 1999'da \%64 olan aşılama hızları 2016 itibariyle \%98'e yükselmiş ve HBsAg seropozitifliği son yıllarda azalırken anti-HBs seropozitifliği artmıştır (2, 15-17). Çalışmamızda Türk gebeler ile mülteci gebeler arasında anti-HBs seropozitiflik oranı sirasıly $\% 38,4$ ve $\% 22,2$ olup aradaki fark istatistiksel olarak anlamlı bulunmuştur $(p<0,001)$. Bölgemizdeki mültecilerin çoğunluğunun Suriyeli olması ve 2011 de ortaya çıkan savaş nedeniyle aşılama ve tarama oranlarının düşmesi bu durumun sebeplerinden biri olarak düşünülebilir (17). Bahat ve ark. (1) da Suriyeli ve Türk gebeleri karşılaştırdıkları çalışmalarında anti-HBs seropozitifliğini Türk gebelerde anlamlı derecede yüksek bulmuşlardır. Ayrıca çalışmamızda gebeler yaş gruplarına bölünmüş olup Türk gebelerde 30 yaş ve altında, 30 yaş üstü gebelere göre anti-HBs seropozitifliği anlamlı derecede yüksek çıkmıştır. Dağ ve ark. (18) da çalışmalarında 18-30 yaş arası hastalarda anti-HBs seropozitifliğini \%58; 30 yaş ve üstü kişilerde \%29 olarak bulmuşlardır. Şahin ve ark. (19) ise hepatit B aşısının rutine girdiği 1998 yılından sonra doğan gebelerde anti-HBs seropozitifliğini diğer yaş gruplarına göre daha yüksek olan $\% 54,5$ oranında bildirmişlerdir. Toplumdaki HBV taşıyıcılarının yaklaşık yarısının HBV'yi perinatal dönemde aldığını bildiren çalışmalar mevcuttur (20). Bu nedenle yaşa bakılmaksızın gebelik riski olan veya gebelik planlayan her kadına hepatit B aşısının yapılması uygun bir yaklaşım olabilir, böylece ilerleyen y1llarda gebelerde anti-HBs seropozitiflik oranlarının \%38 düzeyinden çok daha yüksek oranlara taşınacağını düşünmekteyiz.

Hepatit virüslerinden bir diğeri olan HCV de vertikal yolla yenidoğanlara geçebilmektedir ancak HCV için henüz aşı geliştirilememiştir $(6,21)$. Çalışmamızda antiHCV seropozitifliği \%0,08 oranında bulunmuştur. Ülkemizde yapılan diğer çalışmalara baktığımızda anti-
HCV seropozitifliğini Madendağ ve ark. (12) \% 0,17; Şahin ve ark. (19) \% 0,21; Çakmak ve ark. (22) \% 0,3 oranında bulmuşlardır. Bahat ve ark. (1) anti-HCV seropozitifliğini ise Suriyeli gebelerde $\% 0,1$; Türk gebelerde $\% 0,2$ oranında bulmuşlardır.

Hepatit virüsleri gibi HIV de gebelerde taranması gereken enfeksiyonlardandir. HIV pozitif saptanan gebelerde antiretroviral tedavi hedeflenmeli ve böylece perinatal geçişin önlenmesi ve maternal HIV hastalığının tedavi edilmesi sağlanmalıdır (23). Türkiye de yapılan çalışmalarda gebelerde anti-HIV seropozitifliği \%0 ile 0,1 arasında değişmektedir $(1,24)$. Çalışmamızda Türk ve mülteci gebelerde anti-HIV seropozitifliğine rastlanmamış olup ülkemiz literatürüyle benzer olduğu gözlenmiştir.

Çalışmamızın retrospektif olması nedeniyle gebelere ait doğum sonrası bilgilere ulaşılamamış olması ve aşılama ile geçirilmiş enfeksiyonun ayrımının yapılmamış olması, çalışmamızın kısıtlılığını oluşturmaktadır.

Sonuç olarak, çalışmamızda Türk ve mülteci gebelerin HBsAg, anti-HCV ve anti-HIV sonuçları arasında anlamlı farklılık olmamakla birlikte Türk gebe kadınlarda antiHBs seropozitifliği anlamlı düzeyde yüksek oranda bulunmuştur. Ayrıca yaş grupları açısından da irdelendiğinde Türk gebelerde 30 yaş ve altındaki antiHBs seropozitifliği, 30 yaş üstüne göre daha yüksek bulunmuştur. $\mathrm{Bu}$ durumun en muhtemel nedeni, ülkemizdeki düzenli ve kontrollü aşılama politikalarıdır. Mülteci gebelerde ise Anti-HBs seropozitifliği oldukça düşük bulunmuştur. $\mathrm{Bu}$ durum aşılamanın yetersiz olduğunu göstermektedir. Bu nedenle Hepatit B aşılama programları düzenli olarak takip edilmeli, rutin tarama ve bilinçlendirme programları düzenlenmelidir. Çalışmamızda her ne kadar düşük oranda anti-HCV pozitifliği olsa ve anti-HIV seropozitifliğine rastlanmamış olsa da anti-HCV ve anti-HIV taramasına devam edilmelidir. Çünkü tüm önlemler uygulandığında anneden bebeğe HIV ve HCV geçişinin çok düşük oranlarda olması mümkündür.

Yazarların Katkıları: Fikir/Kavram: S.M.; Tasarım: S.M.; Veri Toplama ve/veya İşleme: S.M.; Analiz ve/veya Yorum: Ş.Y.; Literatür Taraması: S.M.; Makale Yazımı: Ş.Y.

\section{KAYNAKLAR}

1. Yalçın Bahat $P$, Turan G, Yüksel Özgör B, Bağcı Çakmak K. Comparison of hepatitis B, hepatitis C, and HIV seropositivity of Syrian and Turkish pregnant women. Turk J Obstet Gynecol. 2019; 16 (2): 95-9.

2. Tosun S. Pregnancy and hepatitis B virus infection. Mediterr J Infect Microb Antimicrob. 2016; 5: 4

3. Nelson NP, Jamieson DJ, Murphy TV. Prevention of perinatal hepatitis B virus transmission. J Pediatric Infect Dis Soc. 2014; 3(1): 7-12.

4. Centers for Disease Control (CDC). Postexposure prophylaxis of hepatitis B. MMWR Morb Mortal Wkly Rep. 1984; 33(21): 285-90.

5. Gülcü S, Arslan S. Çocuklarda aşı uygulamaları: güncel bir gözden geçirme. Düzce Üniversitesi Sağlık Bilimleri Enstitüsü Dergisi. 2018; 8(1): 34-43. 
6. Jhaveri R, Swamy GK. Hepatitis C virus in pregnancy and early childhood: current understanding and knowledge deficits. J Pediatric Infect Dis Soc. 2014; 3(1): 13-8.

7. Hughes BL, Page CM, Kuller JA. Hepatitis C in pregnancy: screening, treatment, and management. American Journal of Obstetrics and Gynecology. 2017; 217(5): 2-12.

8. Kölgelier S, Demir LS, Demir NA, Özçimen S, Tabak S. Seropositivity of HBsAg and anti-HCV in pregnant women in Adiyaman. Viral Hepatit Dergisi. 2012; 18(3): 98-101.

9. Branson BM, Handsfield HH, Lampe MA, Janssen RS, Taylor AW, Lyss SB, et al. Centers for Disease Control and Prevention (CDC). Revised recommendations for HIV testing of adults, adolescents, and pregnant women in health-care settings. MMWR Recomm Rep. 2006; 55(14): 1-17.

10. Sanhal C, Ataman Ç, Özel Ş, Üstün Y. Gebelikte HIV enfeksiyonu. Jinekoloji-Obstetrik ve Neonatoloji Tip Dergisi. 2018; 15(2): 87-9.

11. Uzun B, Gungor S, Er H, Pektas B, Demirci M. İzmir Atatürk Eğitim Araştırma Hastanesine başvuran poliklinik hastalarında HBsAg, Anti-HCV, Anti-HIV seroprevalansı. Viral Hepatit Dergisi. 2013; 19(3): 123-5.

12. Madendağ Y, Madendağ İ, Çelen Ş, Ünlü S, Danışman N. Seroprevalence of hepatitis B, hepatitis $\mathrm{C}$ and HIV at whole obstetric and gynecologic patients who applied our hospital. Journal of Clinical Obstetrics \& Gynecology. 2007; 17(6): 442-6.

13. Aynioğlu A, Aynioglu O, Akar T, Aydın M, Altunok E. HBsAg, Anti-HBs and anti-HCV seropositivity rates among pregnant women attending a university hospital in Zonguldak. Viral Hepatitis Journal. 2015; 21(1): 31-4.

14. İnci A, Yıldırım D, Seçkin K, Gedikbasi A. Analysis of HbsAg positivity rate before and after vaccination in Turkish and Syrian refugee pregnant women. J Infect Dev Ctries. 2017; 11(10): 815-8.

15. Bakar RZ, Dane B. Gebelerde hepatit B seropozitifliği ve Türk literatürüne bir bakış. Perinatoloji Dergisi. 2016; 24(2): 83-8.

16. Dede A, Çalışkan E. Buldan Göğüs Hastalıkları Hastanesi'ne başvuran hastalarda HBsAg ve Anti HBs seropozitifliği. Düzce Üniversitesi Sağlık Bilimleri Enstitüsü Dergisi. 2015; 5(1): 7-9.

17. Aşgın N, Satılmış Ş. An evaluation of hepatitis B virus and hepatitis $C$ virus frequency and the antihepatitis B surface seropositivity of Syrian refugees in the Karabük province. Viral Hepatitis Journal. 2019; 25(3): 84-7.

18. Dağ Z, Gül S, Işık Y, Tulmaç Ö, Şimşek Y. Kırıkkale bölgesinde yaşayan gebelerde hepatit $\mathrm{B}$ ve hepatit $\mathrm{C}$ seropozitiflik oranlar1. Bozok Tip Derg. 2015; 5(3): 14.

19. Şahin M, Zencir M, Gözübüyük A, Pektaş B. Seroprevalence of hepatitis B surface antigen, antihepatitis B surface and anti-hepatitis C virus among pregnant women residing in Şırnak province. Viral Hepatitis Journal. 2018; 24(1): 7-11.

20. Mistık R. Türkiye'de viral hepatit epidemiyolojisi Yayınların irdelenmesi. Tabak F, Balık I, Tekeli E, editörler. Viral hepatit. İstanbul: İstanbul Medikal Yayıncılık; 2007. s. 9-50.

21. Kose S, Odemis I, Celik D, Gireniz Tatar B, Akbulut I, Ciftdogan DY. Hepatitis A, B, C and HIV seroprevalence among Syrian refugee children admitted to outpatient clinics. Infez Med. 2017; 25(4): 339-43.

22. Çakmak B, Karataş A. Kocaeli bölgesinde yaşayan gebe kadınlarda hepatit B ve C seropozitiflik oranları. Selçuk Tıp Dergisi. 2012; 28(2): 80-2.

23. Sucu M, Çetin C, Özsürmeli M, Khatib G, Çetin C, Evrüke C. Gebelik ve HIV enfeksiyonu. Arşiv Kaynak Tarama Dergisi. 2016; 25(4): 522-35.

24. Çınar Tanrıverdi E, Özkurt Z, Göktuğ Kadığlu B, Alay H, Çalıkoğlu O, Koca Ö, et al. Seroprevalence of hepatitis B, hepatitis C, and HIV in pregnant women from Eastern Turkey. Turk J Gastroenterol. 2019; 30(3): 260-5. 